\title{
¿ Fragmentación y unidad de las organizaciones obreras mendocinas en $1945^{1}$
}

\author{
Mariana Garzón Rogé
}

\begin{abstract}
Resumen: El artículo aborda uno de los principales problemas del espectro sindical mendocino ante el decisivo contexto político de 1945: la alta fragmentación de sus agremiaciones. Los trabajadores organizados evaluaron el panorama de manera diversa e intentaron optimizar su accionar en función de distintas perspectivas. Algunas federaciones obreras bregaron por la unidad sindical, no obstante, las diferencias ideológicas hicieron fracasar las iniciativas. Los sindicatos provinciales que decidieron apoyar a Perón después de octubre de 1945 se vieron proyectados en un camino conjunto de manera abrupta y artificial. En esto residió, en parte, su relativa debilidad posterior. El diseńo de la estructura del Partido Laborista muestra que la unidad sindical tuvo su origen en la contingencia de los sucesos políticos y sólo en menor medida en un efectivo acuerdo de las organizaciones locales. Ese diseño, de todas maneras, se realizó según un criterio que ponía de relieve el peso de los liderazgos anteriores.

Palabras clave: Sindicatos, peronismo, Mendoza, unidad sindical.
\end{abstract}

Fragmentation and unity of labor organizations in Mendoza, 1945

Abstract: The article poses an inquiry about one of the main problems of syndical spectrum in Mendoza before the decisive political context of 1945: the high levels of fragmentation of its associations. Organized workers, judging the scene in different ways, tried to optimize their actions from different perspectives. Some labor federations struggled to unite syndicalism, but ideological differences caused the failure of the initiatives. The provincial unions who decided to support Perón after October 1945 were abruptly and artificially projected on a same path. This is partly the cause of their later relative weakness. The way in which Labor Party was designed showed, however, the strength of local criteria to configure a novel political organization. Even if political events determined unity, previous leaderships prevailed.

Key words: Unions, peronism, Mendoza, syndical unity.

Fecha de recepción de originales: 10/04/2009

Fecha de aceptación para publicación: 12/07/2010

1 Estetrabajo es parte de una investigación en curso sobre los orígenes del primer peronismo en Mendoza. Agradezco los comentarios de los/as eval uadores/as de Quinto Sol .

2 INCIHUSA/CONICET/UNCPBA, e-mail: mariana_garzonroge@yahoo.comar. 
Fragmentación y unidad de las organizaciones obreras mendocinas en 1945

as trayectorias de los sindicatos provinciales ante la emergencia del - peronismo han sido escasamente exploradas, si se las compara con las documentadas y densas interpretaciones propuestas a nivel nacional como espejo de lo que sucedía en Capital Federal y Buenos Aires. Estas investigaciones generales han abordado los problemas vinculados al movimiento obrero del interior como aditivo de lo que sucedía en los poderosos gremios centrales o bien como casos excepcionales en el marco de actividades específicas ${ }^{3}$.

La vida del sindicalismo argentino se vio radicalmente transformada durante el interregno militar de 1943-1946. Por un lado, se operaron cambios en las agencias estatales que regulaban su actividad. Los organismos provinciales pasaron a depender de la nueva Secretaría de Trabajo y Previsión Social a cargo del coronel Perón y los estados subnacionales perdieron su injerencia en materia laboral. Por otro lado, el mapa de organizaciones obreras se modificó como consecuencia de la Ley de Asociaciones Profesionales en octubre de 1945, medida que cimentó una estructura organizativa federal y por ramas de actividad. Por último, un gran contingente de organizaciones sindicales se inclinaron por formar un partido político propio para acompañar al candidato oficial en la salida del régimen hacia fines de 1945, modificando el rumbo de una histórica trayectoria, en la que una parte considerable se había guiado por el principio de prescindencia política ${ }^{4}$.

Los trabajadores organizados en las provincias enfrentaron, en este año decisivo, problemas específicos. En primer lugar, el blanco de sus demandas se desplazó de los gobiernos e instituciones locales a las esferas de la nación. En segundo lugar, la necesidad de reforzar

3 La literatura sobre ed vínculo entre el primer peronismo y las organizaciones de trabajadores es extensa. Algunos de los trabajos clásicos son: Del Campo (2005 [1983]), Di Tella (2003), Doyon (2006 [1978]), Horowitz (2004 [1990]), Murmis y Portantiero (2002 [1971]) y Torre (2006 [1990]). Los desarrollos que abordan los casos provinciales y locales son recientes. Entre otros, el caso de Tucumán ha sido estudi ado por Pavetti (1999), Piliponsky (2008), Rubinstein (2003), Gutiérrez y Rubinstein (2008). El de Buenos Aires ha sido abordado por Marcilese (2009), Mengascini (2008), Nieto (2008). El caso deSanta Feha sido analizado por Prol (2008). El de Neuquén y Río Negro, por Mases y Rafart (2003).

4 Muchos gremios habían partici pado de activi dades comunes con partidos políticos en el pasado. Sin embargo, la idea de un partido de base si ndical fue total mente nueva. 
o crear vínculos con gremios de su actividad en el ámbito nacional dejó de ser, para muchos, un anhelo remoto para convertirse en un imperativo. Finalmente, el ingreso a la vida política no constituyó una simple apuesta por Perón, sino un horizonte de organización obrera en el que primero debían sortearse las divisiones internas y lidiar con el espacio meridiano de la política local.

El estudio de la vida sindical en el interior puede iluminar cómo se produjeron estos complejos procesos y vislumbrar de qué modo la llegada del peronismo al poder afectó los rasgos de un movimiento argentino que, según Juan Carlos Torre (2006:40), recién entonces emergió como tal. También es posible que nuevos aportes permitan comprender, por un lado, la larga atadura del peronismo con el sindicalismo en tanto forma regia de unificación federal. Y, por otro lado, es factible que los espacios provincianos y locales sean especialmente aptos para indagar mejor acerca de la vida obrera durante el peronismo ya que las organizaciones, por ser más pequeñas, gozaban de menos atención por parte del Estado, tanto al momento de recibir los beneficios como de ser regimentadas.

Este artículo aborda, específicamente, los comportamientos que las agrupaciones sindicales de Mendoza adoptaron frente a los intensos procesos que la Argentina vivió durante el año 1945. La estrategia de Perón de conquistar a un sector social medio y a dirigentes radicales, ya se había desmoronado y sus ojos estaban puestos en los gremios. Sin embargo, esa opción no fue inmediatamente aceptada por los trabajadores, quienes se movilizaban en busca de un futuro lugar en la salida de la crisis política y social. ¿Qué iniciativas tomaron? ¿Qué especulaciones hicieron? ¿Qué estrategias promovieron? Este trabajo pone bajo la lente una cuestión que preocupaba y que afectó a los gremios mendocinos durante esos meses: la unidad sindical. Diversos intereses, propuestas y reacciones en torno a este asunto definieron, en parte, los rasgos del proceso que tuvo como punto neurálgico la formación del Partido Laborista en Mendoza.

El desarrollo de este artículo cuenta de dos secciones. En un primer momento se realiza una presentación del fragmentado mapa obrero provincial, se presta atención a la trayectoria y a la composición de las federaciones existentes, a sus comportamientos en relación al gobierno militar y a sus rasgos ideológicos. En la segunda parte, se indaga en los escenarios que los trabajadores tuvieron en cuenta para guiar sus prácticas, se narran los intentos de unificación sindical y se 
explican las razones de sus relativos éxitos y fracasos. El seguimiento de las interpretaciones acerca de lo que estaba sucediendo y de las prácticas sindicales que se accionaron permitirá acceder a los temores, dudas y esperanzas de un quebradizo mundo obrero provincial que sentía que se acercaban definiciones transcendentales y quería ocupar un lugar en esa nueva configuración.

\section{Organizaciones obreras en Mendoza durante la Revolución de Junio}

A fines de 1944, existían en Mendoza cuatro conglomerados sindicales principales. A estas organizaciones, se sumaban los gremios que no tenían vínculos institucionalizados en la esfera provincial, algunos de los cuales eran de los más numerosos de la provincia. Tal es el caso de los trabajadores ferroviarios y de los empleados de comercio. Estos sindicatos no estaban integrados a las federaciones locales debido a los estrechos vínculos que sostenían con sus respectivas organizaciones a nivel nacional.

\subsection{La Federación Obrera Provincial Mendocina (FO PM)}

La FOPM fue la tradicional central obrera de Mendoza. Sus orígenes se remontaban por lo menos hasta 1921, cuando los sindicatos que allí se nuclearon eran voceros del anarquismo. Después del régimen militar de 1930, la dirigencia había adherido a la tendencia del sindicalismo revolucionario. A mediados de esa década, bajo la influencia del socialismo en la provincia, accedieron a la cúpula de la FOPM militantes más abiertos a la idea de comprometer a la acción obrera con ciertas banderas políticas. Esta experiencia no pudo sostenerse y la organización se disolvió. La recreación de la central se produjo en 1940 como iniciativa de algunos de sus antiguos dirigentes y sindicatos ${ }^{5}$, en el marco del tratamiento de la Ley Orgánica del Departamento Provincial del Trabajo que el Poder Ejecutivo local, en manos del Partido Demócrata Nacional, impulsó a fines de 1939.

El resurgimiento de la FOPM se realizó bajo la consideración de que había que sostener una organización intersindical que respetase el

5 El Obrero Gráfico de Mendoza, en adelante, OGM, enero de 1941. 
principio de la prescindencia política, pero con un renovado concepto acerca de la injerencia del Estado en la política sindical. La federación consideraba que el Estado podía buscar una mejora entre las fuerzas del trabajo y las del capital, aunque siempre con el interés de hacer sostenible al sistema capitalista. La vía estatal constituía un medio donde era factible "batir al adversario en su propio reducto" y sólo la organización sindical podía promover el mejoramiento definitivo de los sectores laboriosos ${ }^{6}$.

La FOPM se ocupó a comienzos de los años cuarenta de hacer saber a sus bases que seguía una ideología estrictamente sindicalista. El sindicalismo era una tendencia clasista interesada en representar una identidad obrera y no necesariamente a un "pueblo". En sus inicios, su ideología era revolucionaria y planteaba la destrucción del sistema capitalista y no su humanización; sostuvieron la bandera de la prescindencia política pero su concepción del Estado se modificó con el tiempo (Del Campo 1986:8). En ese sentido, la FOPM aspiraba a una "autonomía de sus sindicatos integrantes, libres del centralismo devastador, y una acción concreta en las luchas, fortificada ésta con el concurso de un numeroso grupo de militantes"7. La organización estableció relaciones con el Departamento Provincial de Trabajo sólo en la medida en la que éste colaboró en resoluciones favorables. El Secretario General, el gráfico Isaac Espinosa, exponía su pensamiento al respecto:

"El Sindicalismo... va hacia la realidad y no hacia la utopía. Y en ese carácter, no puede ser anarquista porque su doctrina es concreta y no abstracta. No puede ser comunista ni socialista porque la acción sindical está reñida con los procedimientos electoralistas que desvían a los trabajadores en su organización de clase y les anulan como elementos de lucha para la defensa de sus propios intereses y de sus derechos de asalariado; más aún, porque la estructura electoralista de esas agrupaciones deforman los principios sindicales, tergiversando la misión del Sindicato, e insensiblemente, van formando una conciencia apta para las dictaduras"8.

6 OGM, enero de 1940.

7 OGM, enero de 1941.

8 OGM, enero de 1941. 
A comienzos de 1945, las organizaciones de la Capital mendocina reunidas en la FOPM eran el Sindicato de Artes Gráficas, el Sindicato de Mozos y Anexos, la Asociación General de Músicos, el Sindicato de Obreros Panaderos, el Sindicato de la Industria de la Carne, el Sindicato de Cafeteros, Cocteleros y Anexos, el Sindicato de Obreros Fideeros, la Cámara Sindical de Cocineros y Anexos, el Sindicato Obrero de la Industria del Calzado, la Unión de Operadores Cinematográficos, el Sindicato de Galvano-Técnicos, Plateros, Bronceros y Afines, la Sociedad de Obreros del Vestido, el Sindicato del Personal de Lavaderos, Tintorería y Afines, y el Sindicato Obrero de la Industria de la Madera. Del departamento sureño de San Rafael participaban la Sociedad de Empleados de Comercio e Industria, el Sindicato de Obreros Panaderos, el Sindicatos de Mozos, el Sindicato de Obreros Fideeros, la Sociedad de Oficiales Sastres y Afines, la Sociedad de Artes Gráficas, el Sindicato de Mecánicos, Metalúrgicos y Anexos, el Sindicato de Obreros de la Madera, el Sindicato de Obreros Municipales y la Sociedad de Camioneros. También se nucleaban allí organizaciones de otras localidades como el Sindicato de O breros de la Alimentación de Monte Comán y las secciones del Sindicato de la Carne de los departamentos de San Martín y Junín 9 . Algunos de éstos eran los gremios de más larga tradición en el mundo obrero provincial. El Sindicato de Artes Gráficas, cuyo ascendente sobre la FOPM era notorio, había sido fundado en $1905^{10}$. Los sindicatos de las industrias panadera, maderera, de la carne, toneleros, fideeros y los gremios cocineros y mozos, actuaban en la provincia desde fechas anteriores a 1920.

El presidente de la FOPM en 1945 era Juan Curto. Esta figura representaba a la vieja guardia sindical mendocina, ya que militaba en el gremio de la madera y en la organización intersindical desde los años en que ésta adhería al anarquismo ${ }^{11}$. Curto fue uno de los "anarcosindicalistas" a los que Benito Marianetti culpó por el retraso de los obreros locales en sumarse al socialismo.

9 Los Andes, en adelante, LA, 10.03.1945.

10 OGM, febrero y marzo de 1941.

11 Despertar Obrero, diciembre de 1932. 


\subsection{La Federación de Sindicatos Unidos O breros (FSU O)}

La Federación de Sindicatos Católicos Obreros (FSCO) se fundó en julio de $1944^{12}$ bajo el lema de "Dios, Patria y U nión" y decía congregar a 7.000 asociados $^{13}$. En ese momento cuatro sindicatos habían suscripto el acta constitutiva: el Sindicato de la Compañía de Electricidad Los Andes, el Sindicato del Personal de la Dirección de Vialidad Provincial, el Sindicato Obrero del Personal de Transporte de Pasajeros (de la empresa C.I.T.A.) y el Sindicato del Personal de Micros y Ómnibus ${ }^{14}$. A las cuatro entidades fundadoras se habían unido luego el Sindicato de la Municipalidad de la Capital, el Sindicato de la Dirección de Salubridad, el Sindicato de Urbanismo y Parques, el Sindicato del Matadero y Frigorífico Mendoza, el Sindicato Unión de Lustradores de Calzado, el Sindicato de Choferes Profesionales, el Sindicato de Corralones, Aserraderos y Materiales de la Construcción y el Sindicato de los Repartidores de Pan ${ }^{15}$.

Los integrantes de esta federación, en especial sus miembros fundadores, ocupaban sectores primordiales para el normal desarrollo de la vida cotidiana de Mendoza. Louise Doyon ha manifestado la alta visibilidad que tiene un conflicto obrero en este tipo de actividades y la consiguiente presión que se puede ejercer desde ellas, al explicar que "la opinión pública equipara el bienestar de la comunidad con el funcionamiento in interrumpido de numerosos servicios que incluyen transporte, comunicaciones, salud y gobierno" (2006:282).

Las fuentes documentales disponibles no permiten rastrear un pasado común entre los integrantes de estos gremios. Algunos de estos sindicatos se habían constituido en 1944, pero no eran sindicatos paralelos creados por el Estado ${ }^{16}$. Los lenguajes y las prácticas sindicales de esta federación durante los años de la Revolución de Junio permiten guardar la sospecha de que se trataba de organizaciones de larga data y con lazos de solidaridad estables ${ }^{17}$.

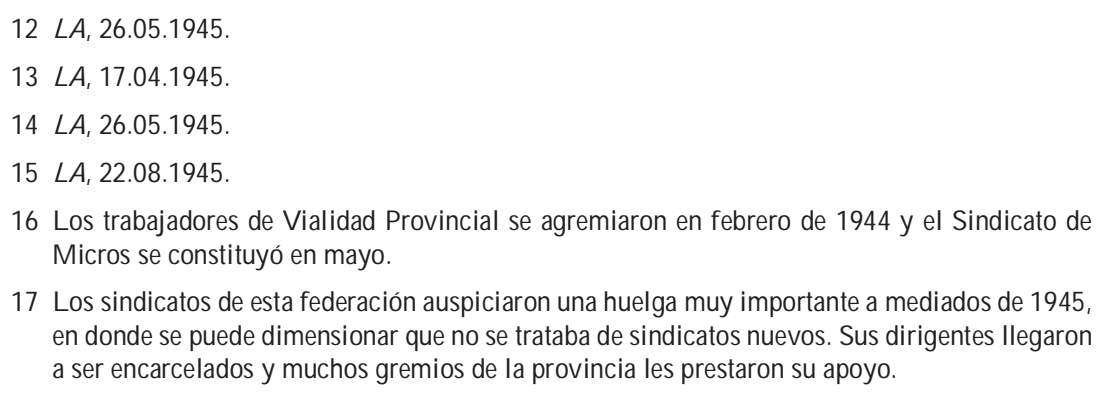

17 Los sindicatos de esta federación auspi ciaron una hue ga muy importantea medi ados de 1945, en donde se puede dimensi onar queno se trataba desi ndicatos nuevos. Sus di rigentes llegaron a ser encarcelados y muchos gremios de la provincia les prestaron su apoyo. 
El sello católico de la federación no pudo sostenerse. Cuando las luchas internas en el régimen militar terminaron con el ala más clerical que había imperado en los meses que siguieron a la toma del poder, la FSCO decidió deshacerse de su pía denominación y reformar sus estatutos. El 6 de abril de 1945, una asamblea determinó el cambio de nombre por el de Federación de Sindicatos U nidos O breros (FSUO). La transformación no fue cosmética, ya que incluso le hizo perder adherentes ${ }^{18}$. El asesor legal, Jorge Lahún, se retiró de la organización "ante la oposición sistemática que se hacía a los principios específicamente cristianos que figuran en el texto [del estatuto], y que son inspirados en la más pura doctrina social cristiana contenida en las Encíclicas Papales, especialmente en la 'Rerum N ovarum', como así también en los estatutos de la Confederación Francesa de los Trabajadores Cristianos" ${ }^{\prime 19}$. Bajo la bandera de la prescindencia política, con aires católicos y la aceptación de las mejoras que se le ofrecían, la FSUO apoyó ese año al gobierno de Farrell, si bien condenó diversos aspectos de la administración provincial. Fue, incluso, la organización que promovió más medidas de fuerza bajo el liderazgo de Albino Sánchez.

\subsection{La Agrupación Gremial Argentina (AGA)}

La AGA era una organización forjada al calor de la Delegación Regional de Trabajo en 1944. Muchos de sus grupos fueron directamente organizados entre trabajadores sin filiaciones aunque su objetivo más evidente era constituir sindicatos paralelos a los que habían sido castigados por la represión del régimen, en especial, los gremios de la construcción y de la industria vitivinícola. De hecho, Antonio D'Amore, vértice de la agrupación, se presentaba como obrero de la construcción. En 1945 se constituyeron en miembros de la AGA o fueron formados por ella el Sindicato de Agrarios, el Sindicato de Toneleros, el Sindicato de la Industria Lechera, el Sindicato de Obreros Metalúrgicos y Anexos, el Sindicato de Obreros de Mosaico y Anexos, el Sindicato de Transportadores de Vino en Tanques, el Sindicato de Canteros y Caleras, el Sindicato de Trabajadores de Bodega, el Sindicato de Industrias Químicas, el Sindicato de Oficios Varios, Lavadores

18 LA, 26.05.1945 y 03.01.1945.

19 Solicitada publicada en LA, 17.04.1945. 
y Engrasadores de Autos, el gremio de los Recolectores y Empaquetadores de Frutas, el Sindicato de la Industria de la Harina, el Sindicato de Peluqueros, el Sindicato de Electricistas y Anexos, y el Sindicato de Trabajadores de Pavimentación y Caminos.

La AGA era de las escasas entidades reconocidas por la Delegación Regional de Trabajo y la única reconocida como federación. Cualquier conjunto de obreros que se constituía en sindicato bajo la égida de la AGA automáticamente era reconocido por la oficina estatal. Esta ventaja no eliminó los problemas que se plantearon en su interior cuando los partidos políticos pudieron volver a operar en la provincia a mediados de 1945. Entonces, se destapó la disputa entre la AGA y las viejas dirigencias obreras; el caso más resonante fue la existencia de dos núcleos que se adjudicaron la representación de la Unión de Obreros Cementistas General Las Heras²0.

\subsection{La Central de Trabajadores Mendocinos (CTM)}

La organización más afectada por la represión de los primeros meses de la Revolución de Junio fue el Sindicato Obrero de la Construcción, lugar donde confluían numerosos grupos por oficio de la actividad. En el corazón de esa organización estaban los gremios cementistas de las portentosas fábricas Minetti y Corcemar, ubicadas en el departamento de Las Heras. Sus dirigentes más sobresalientes fueron encarcelados en $1943^{21}$, los locales clausurados y sus pertenencias incautadas por realizar actividades comunistas ${ }^{22}$. Este sindicato, cuando pudo reactivarse gracias al levantamiento del estado de sitio, fue el alma de la Central de Trabajadores Mendocinos. Sin embargo, para ese entonces ya se habían creado varios sindicatos paralelos con la intención de reemplazarlo.

20 LA, 27.08.1945.

21 Dirigentes de ese sindicato, tales como Agustín Espósi to y Roberto Vélez, continuaban presos a mediados de 1945.

22 En Mendoza, un desprendimiento del Partido Socialista, el Partido Social ista Obrero (a cuya cabeza se hallaba Benito Marianetti) militaba a la par del Partido Comunista (conducido por Ángel Bustelo). Los dos partidos actuaban en la vida política local desde hacía al gunos años como si fueran el mismo partido. Sin embargo, el PC operaba en Mendoza clandestinamente desde 1936. El PSO fue disuel to por el decreto N 777 G, del 16 de julio de 1943. Anales de Legislación Argentina. Una vez legalizados los partidos políticos hacia agosto de 1945, el PSO se fundió en el PC definitivamente. 
Marianetti resaltó en sus memorias sobre las luchas sociales en Mendoza que la CTM era una central "de orientación clasista" un grupo que "nucleaba a una cantidad apreciable de sindicatos, es decir, a los más combativos y [que] tuvo que soportar el mayor peso de la represión" (1970:120/122). En realidad, Marianetti agrandó la capacidad de aglutinamiento de esta entidad. Es más, es posible que la CTM ni siquiera haya funcionado formalmente como tal. Existieron nucleamientos que tenían vínculos estables con el Sindicato de la Construcción, pero no se puede afirmar que se hayan realizado reuniones, actos, ni ningún tipo actividad en común. El Sindicato de Obreros Vitivinícolas de Godoy Cruz, que también tenía alguna influencia de dirigentes comunistas, a mediados de 1945 había logrado reorganizarse y había acogido con entusiasmo las ventajas conquistadas en el marco del gobierno militar. La Sociedad de Empleados de Comercio, dirigida por socialistas que rechazaban el acercamiento al gobierno militar que el gremio porteño promovía, tenía un excelente vínculo con la FSUO y la FOPM ${ }^{23}$.

\section{La unidad sindical en Mendoza, un problema en tiempos de política}

El tránsito de las organizaciones obreras durante el decisivo año 1945 estuvo signado por el desconcierto, la cautela y el cálculo ${ }^{24}$. En junio, el Manifiesto de las Fuerzas Vivas alentó a algunos sindicatos metropolitanos a abandonar provisoriamente esas actitudes. Ese documento no sólo criticó aspectos políticos del gobierno, sino que se abalanzó explícitamente contra su programa de reformas sociales. Este ataque justificó la reacción de la CGT en Capital Federal quien, en el acto del 12 de julio, respaldó claramente a la Secretaría de Trabajo y Previsión (STyP) conducida por Perón. Poco después, el apoyo de la central obrera se retiró de la escena pública y aguardó hasta las jornadas de octubre para volver a defender al coronel (Torre 2006:98) Se trató de un rumbo comprensible a la luz del vertiginoso proceso polí-

23 Esta entidad funcionó como intermediaria entre la FSUO y la intervención federal para resolver el conflicto huelguístico de junio.

24 Algunos de los análisis más importantes sobre el trabajoso proceso de reacomodamiento de los grupos obreros durante estos meses son los de Del Campo (2005), Doyon (2006) y Torre (2006). 
tico que vivía el país. En él, si se tenía en cuenta la creciente movilización opositora que comenzó a manifestarse a partir del levantamiento del estado de sitio, ya no era tan evidente que Perón fuera a triunfar. En ese marco, los gremios provinciales comenzaron a evaluar los escenarios posibles con los que se podrían encontrar. Aunque algunos sentían simpatía por la obra social del gobierno militar, el objetivo de todos era obtener un sitio del lado de quien ganara la batalla desatada en los ámbitos políticos. La bandera de la prescindencia política que algunas agrupaciones levantaron, origen de dudas pero también potencial epicentro de una actitud pragmática en relación a la coyuntura, estaba en el ojo de la tormenta. Las mejoras que se habían fomentado en el mundo laboral no eran desdeñables. Sin embargo, la única certeza de las organizaciones gremiales en esos meses de aceleración del tiempo histórico era que, en vistas a un escenario inminente, había que abandonar el lugar de marginalidad en el que se encontraban.

¿Optar por Perón? ¿Por un militar, tildado de filofascista, anticomunista? La AGA no podía hacerse estas preguntas. En cambio la FSUO, cuando el clima era adverso a Perón, llegó a participar con un orador en el acto por la victoria aliada organizado por la oposición ${ }^{25}$. Si bien muchos cambios se habían operado en la provincia, la política obrerista del gobierno todavía no impactaba en Mendoza de manera tan visible como parecía suceder en Buenos Aires. Se firmaban convenios colectivos pero no se hacían respetar. La polémica jurisdicción del Departamento de Trabajo, ahora convertida en Delegación Regional de la STyP, dificultó el alcance de las medidas de esa agencia en la escala federal. Había que tener un vínculo directo con las altas esferas oficiales para vehiculizar reclamos, porque la seccional del trabajo no respondía efectivamente a las demandas obreras. Los conflictos obreros de junio propulsados por la FSUO habían Ilevado a sus dirigentes a preguntarse si la obra de Perón no era una "hermosa, optimista y rosada ficción" ${ }^{\prime 26}$. Lo único que aseguraba sin dudas la Delegación Regional de Trabajo era la creación de sindicatos paralelos.

¿Optar por la oposición? Este era el plan de los gremios comunistas de la CTM. Sin embargo, era a todas luces evidente que el variopinto conglomerado de agrupaciones políticas que se había nucleado (protagonizado por una alianza entre comunistas y demócratas nacio-

25 LA, 03.07.1945.

26 LA, 02.07.1945. 
nales ${ }^{27}$, sólo quería reunir tras de sí a los obreros con el único fin de evitar que Perón accediera al poder. ¿Bregar por la democracia al lado de los conservadores? ¿Qué clase de vínculo podía establecerse con una oposición que en su primer acto público repartió "versiones fonéticas" de la marsellesa para que el vulgo pudiera entonarla ${ }^{28}$ ¿ ¿No eran los trabajadores el blanco de los ataques racistas con que la oposición intentaba mancillar la imagen de Perón ${ }^{29}$ ?

En esa situación signada por dilemas y contradicciones, los gremios mendocinos empezaron a ensayar estrategias para enfrentar el inminente desenlace de la crisis nacional en las mejores condiciones posibles. El viejo anhelo de la unificación de los trabajadores organizados en la provincia se puso en acción. La necesidad de materializar esa unidad se fortaleció, no sólo ante la centralidad que empezó a tener en la escena política los trabajadores, sino también por la profusión de organizaciones paralelas y la distribución focalizada de beneficios y puniciones. Las demandas obreras en la provincia se seguían haciendo a los patrones locales y las medidas de fuerza necesitaban de la colaboración de los sindicatos vecinos.

Fue la FOPM quien propulsó las iniciativas unitarias. Por un lado, la corriente sindicalista era naturalmente proclive a fomentar la unidad y propugnaba que en la militancia sindical las identidades políticas debían ser dejadas de lado, ya que generaban divisiones contraproducentes. Por otro lado, algunos de sus gremios conocían bien las ventajas de la organización intersindical, porque ellos participaban de organizaciones federadas. Tal es el caso de la Federación Argentina de Trabajadores de la Imprenta que había podido reunirse sólo cuando se calmaron los conflictos entre sindicalistas y socialistas en el gremio gráfico. Por último, la FOPM posiblemente vio en el contexto de 1945 una oportunidad de reforzar su tradicional predominio en la provin-

27 Esa convergencia política fue explorada en Garzón Rogé(2010).

28 Las "versiones fonéticas" se repartieron en un acto de homenaje al fin de la Segunda Guerra Mundial organizado por los partidos de izquierda, el PDN y varias organizaciones filiadas a ellos. LA, 03.06.1945.

29 Un dibujo aparecido en el Diario de Mendoza, hoja de combate de la exótica alianza política entre comunistas y conservadores mendocinos que se editó entre abril y noviembre de 1945 (dirigida por Benito Marianetti y Emilio Descotte), es muy expresivo del factor racista que nucleó al antiperonismo. El dibujo se titul aba "TIRO AL NEGRO” y mostraba una cabeza de un negrito, ruludo, ocupando el centro de un juego de dardos. Cuatro hombres de tez blanca se veían de espaldas tirándole objetos. Cada uno de esos hombres se identificaba con un cartel: "parti dos políticos", "comerciantes eindustriales", "universitarios" y "sindicatos obreros". Diario de Mendoza, 27.06.1945. 
cia. A comienzos de ese año, el Sindicato de Artes Gráficas había formado un comité para auspiciar la creación de un régimen jubilatorio para los obreros industriales ${ }^{30}$. Luego, en marzo, el IV Congreso de la FOPM planteó como punto principal de su agenda la unidad de los trabajadores mendocinos ${ }^{31}$.

Un intento de unificación que asumió banderas económicas en mayo de 1945 fue la formación de una Comisión Pro Abaratamiento de la Vida. La iniciativa era de la Sociedad de Empleados de Comercio y contó con el apoyo de la FOPM, la FSUO y la AGA. La consigna aglutinante fue el combate contra el aumento de los precios y el estancamiento de los salarios. El plan de lucha que se elaboró en esa oportunidad resolvía no aceptar aumentos en los artículos de primera necesidad, reclamar rebajas generales y exigir el respeto del decreto de alquileres ${ }^{32}$. También se propuso que los sindicatos realizaran estudios acerca de posibles medidas para abaratar los productos que producían y estudios para determinar las ganancias de las industrias y de los comercios en relación a los salarios. Además, se planteó crear una cooperativa de consumo y realizar un acto público conjunto para exigir al Estado políticas de vivienda popular y representación en la Junta de Abastecimiento ${ }^{33}$.

No obstante el éxito relativo de esta reunión, la FSUO y la AGA se inquietaron cuando se plantearon cuestiones de índole política. La AGA se retiró de la Comisión Pro Abaratamiento cuando la intervención federal hubo concedido representación a las tres federaciones en la Comisión de Abastecimiento ${ }^{34}$. La FSUO, por su parte, hizo público que sus delegados sólo habían asistido a la reunión intersindical con el objetivo de tratar los problemas relativos a la carestía de la vida y no para constituir un frente obrero opositor:

\footnotetext{
30 LA, 29.01.1945.

31 LA, 04.03.1945.

32 Decreto $\mathrm{N}^{\circ} 766$, del 14 de julio de 1943 fija la escala de rebaja de los alquileres. Decreto $\mathrm{N}^{\circ}$ 862, de 27 de julio de 1943 aclara disposiciones del decreto № 766. Anales de Legislación Argentina.

33 LA, 30.05.1945.

34 Se otorgó representación en la J unta a tres delegados obreros (uno por la FSUO, otro por la FOPM y otro por laAGA). Horowitz ha señal ado que "durante la década de 1930, e incluso antes, los si ndicatos habían recurrido al gobierno. Lo que cambió después de 1943 fue la actitud del gobierno, no la de los sindicatos" (2004:318).
} 
“dado su carácter de entidad gremial, absolutamente apolítica y ajena a toda ideología de derecha o izquierda, consecuente con sus principios de dedicar todos sus esfuerzos a la mejor defensa de los intereses gremiales y fiel a los propósitos... que pudieran entorpecer el camino que se ha trazado, de defender, proteger $y$ unir a los auténticos trabajadores, [la FSUO declara que] no ha considerado en ningún momento la unificación que auspicia la Sociedad de Empleados de Comercio... y que mantiene sus delegados al solo efecto y con instrucciones categóricas y precisas de considerar solamente el abaratamiento de la vida" ${ }^{35}$.

En julio de 1945, la FOPM refrescó su interés unitario. La nueva iniciativa era propiciar una Comisión Intersindical Pro Unidad Obrera. Los sindicatos comunistas, ahora reintegrados, eran fervientes propulsores de la unidad, aunque lo hicieron en función de apoyar un frente opositor antifascista en contra del gobierno militar. A pesar de que la FSUO estuvo ausente, los organizadores insistieron en que esta federación debía ser convocada nuevamente. Su reputación había sido consagrada después de una huelga -en junio- que había movilizado a muchos gremios obreros ${ }^{36}$. La AGA fue excluida, a pesar de que intentó acreditar delegados. El límite de lo tolerable en la nueva Comisión estaba dado por la independencia frente a las técnicas de cooptación del gobierno, si había simpatía o no por él no era importante. En la reunión realizada el 26 de agosto en la sede de la FOPM se acreditaron delegados de 34 sindicatos y se propuso crear una Federación Única de Trabajadores Mendocinos que mantuviese "la más absoluta independencia sindical de todo partido político, credo o racial y del Estado" 37 .

La Comisión Pro Unidad se encontraba aún inmadura cuando se inició el momento terminal de la crisis política a mediados de septiembre ante la populosa Marcha de la Constitución y la Libertad, la reimplantación del estado de sitio, el pedido opositor de entregar el gobierno a la Corte Suprema, el encarcelamiento del jefe de la STyP, la movilización plebeya de mediados de octubre y la liberación del Perón. La dimensión que tomaron los enfrentamientos políticos alentó a algunos sindicatos a abandonar sus resquemores de ser identificados

35 LA, 26.05.1945.

36 LA, junio de 1945.

37 La Libertad, 27.08.45. El detal le de esta reunión en Garzón Rogé (2007). 
como oficialistas. La FSUO y, por supuesto la AGA, se manifestaron a favor del gobierno en octubre de 1945 y a ellos se sumaron algunos miembros de la FOPM.

\section{Palabras finales}

Walter Little señaló con respecto al Partido Laborista que acompañó a Perón en las elecciones de 1946 que "los laboristas siempre han suscitado una gran nostalgia" ya que en ellos se creyó ver "la posibilidad de crear una Argentina democrática, reformista y armónica que Perón pervirtió trágicamente por su negativa a aceptar la crítica y la heterogeneidad. Esa visión es errada. El Partido Laborista fue un movimiento ad hoc, que no había sido puesto a prueba, ideológicamente derivado de otras orientaciones y tácticamente confuso" (1979:351). La historia de las organizaciones obreras mendocinas constata, ciertamente, que la aceleración de los acontecimientos después de septiembre de 1945 obligó a darse un camino conjunto a quienes no estaban en principio dispuestos a hacerlo. ¿Faltó tiempo? Es presumible que la respuesta sea negativa. La unidad se precipitó solamente $-y$ aunque escape a este trabajo, hay que decir que de manera enclenque ya que no tardó en mostrar sus fisuras luego- en torno a lo que Perón significaba en ese momento: una opción no tradicional donde parecía que todo estaba por hacerse y con un espacio considerable para las reivindicaciones plebeyas.

Los trabajadores de la provincia no fueron masa de maniobra o espejo en miniatura de lo que sucedía en Buenos Aires, avanzaron sobre el contexto según sus criterios, valores y estrategias para posicionarse frente a la salida política. Muestra de ello es que la precipitada unidad que se produjo en los últimos días de octubre con la formación del Partido Laborista local no hizo tabla rasa de las diferencias internas. Esa formación respetó una estructura de jerarquías sindicales provinciales precedente al otorgar el primer lugar (más y mejores cargos) a la FSUO, el segundo a miembros de la FOPM y el tercero a los de la $\mathrm{AGA}^{38}$. Ese diseño da cuenta del peso que tuvieron los liderazgos

38 Partido Laborista de Mendoza: Presidente: Albino Sánchez (FSUO), Vicepresi dentes: $1^{\circ} \mathrm{J}$ uan Curto (FOPM) y $2^{\circ}$ A mílcar Illuminatti (AGA), Secretario General: José Chirino Domínguez (FSUO), Tesorero: Juan de la Torre (FOPM), Protesorero: Antonio D'Amore (AGA), Vocales: Esteban Obredor (FSUO), Ramón Lino Gómez (FOPM), Mart́n Funes (FOPM), Nicanor 
anteriores y las jerarquías sindicales provinciales en la configuración de una unidad sindical mendocina, aunque ella haya tenido su origen más en la contingencia de los sucesos políticos que en un efectivo acuerdo de las organizaciones locales.

\section{Referencias bibliográficas}

DEL CAMPO, Hugo. El "sindicalismo revolucionario". 1905-1945. Selección de textos, Buenos Aires: CEAL, 1986.

- Sindicalismo y peronismo. Los comienzos de un vínculo perdurable, Buenos Aires: Siglo XXI, 2005.

DI TELLA, Torcuato. Perón y los sindicatos. El inicio de una relación conflictiva, Buenos Aires: Ariel, 2003.

DOYON, Louise. Peróny los trabajadores. Losorígenes del sindicalismo peronista, 1943-1955, Buenos Aires: Siglo XXI, 2006.

GARZÓN ROGÉ, Mariana. "El 26 de agosto de 1945 en Mendoza. Un acercamiento a la cultura política de aquellos días". Jornadas de Historia y Memoria de la dirigencia política argentina. Córdoba: Centro de Estudios Avanzados, julio de 2007.

- “De nacionalistas a antifascistas: los conservadores mendocinos ante la irrupción militar de 1943". II Jornadas de Historia Política. El Bicentenario en perspectiva comparada. Mendoza: Universidad Nacional de Cuyo, abril de 2010.

GUTIÉRREZ, Florencia y Gustavo RUBINSTEIN. “De la hegemonía sindical al peronismo 'político'. La reestructuración del partido peronista tucumano, 1949-1952". Primer Congreso de Estudios sobre el Peronismo. Mar del Plata: Universidad de Mar del Plata, noviembre 2008.

HOROWITZ, Joel. Los sindicatos, el Estado y el surgimiento de Perón 1930/1946, Buenos Aires: Universidad Tres de Febrero, 2004.

LITTLE, Walter. "La organización obrera y el Estado peronista, 19431955". Desarrollo Económico, Vol. 19, nº 75:331-376.

Cardúmer (FSUO), Gabriel Prieto (FSUO), Félix Cruz Quinteros (AGA). La lista fue extraída de LA, 18.11.1945. Sin embargo, las pertenencias federativas han sido restituidas a partir de cruces de información realizados por la autora. 
MARCILESE, José. "El movimiento obrero bahiense en vísperas del peronismo", en: M. Cernadas y J. Marcilese, eds., Política, sociedad y cultura en el sudoeste bonaerense. Bahía Blanca: EdiUNS, 2009:101-112.

MARIANETTI, Benito. Las luchas sociales en Mendoza. Mendoza: Ediciones Cuyo, 1970.

MASES, Enrique y Gabriel RAFART. "La patria peronista en la norpatagonia: notas sobre el origen del peronismo en Río Negro y Neuquén", en: D. Macor y C. Tcach, eds., La invención del peronismo en el interior del país. Santa Fe: UNL, 2003:385-436.

MENGASCINI, Hugo. "Conflictos y huelgas ferroviarias durante el periodo peronista. El caso de los trabajadores peronistas de Tandil". $3^{\circ}$ Jornadas sobre la política en Buenos Aires en el Siglo XX. Mar del Plata: Universidad Nacional de La Plata, agosto 2008.

MURMIS, Miguel y Juan Carlos PORTANTIERO. Estudios Sobre los orígenes del peronismo. Buenos Aires: Siglo XXI, 2002.

NIETO, Agustín. "Conflictividad obrera en el puerto de Mar del Plata: del anarquismo al peronismo. El Sindicato Obrero de la Industria del Pescado, 1942-1948". Revista de Estudios M arítimos y Sociales, $n^{\circ} 1,2008: 35-44$.

PAVETTI, Oscar. "Sindicalismo azucarero y peronismo (1949)", en: L. Bonano, coord., Estudios de historia social de Tucumán. Tucumán: Facultad de Filosofía y Letras, 1999.

PILIPONSKY, Esteban. "La estatización del movimiento sindical tucumano (1943-1946)". Primer Congreso de Estudios sobre el Peronismo. Mar del Plata: Universidad de Mar del Plata, noviembre 2008.

PROL, Mercedes. "El Partido Peronista en Santa Fe y el movimiento obrero. Relaciones de poder". Primer Congreso de Estudios sobre el Peronismo. Mar del Plata: Universidad de Mar del Plata, noviembre 2008.

RUBINSTEIN, Gustavo. "El Estado peronista y la sindicalización de los trabajadores azucareros", en: D. Macor y C. Tcach, eds., La invención del peronismo en el interior del país. Santa Fe: UNL, 2003:319-363. 
Mariana Garzón Rogé

TORRE, Juan Carlos. La vieja guardia sindical y Perón. Sobre los orígenes del peronismo. Buenos Aires: Universidad Tres de Febrero, 2006. 